\title{
Aplicação de ensaios não destrutivos no processo de fabricação de bases metálicas dos elevadores de cremalheira
}

Application of Non-destructive tests in the process of manufacturing metallic bases of rack elevators

\author{
Valber Mario da Costa Silva 1 \\ Francisco Ilo Bezerra Cardoso ${ }^{1}$ \\ Valdézio José Pininga de Souza ${ }^{1}$ \\ ${ }^{1}$ Escola Politécnica de Pernambuco, Universidade de Pernambuco, Recife, Brasil, \\ E-mail do autor principal: Valber Mario da Costa Silva valber_mario@hotmail.com
}

\section{Resumo}

O estudo tem por objetivo apresentar o processo de fabricação e os ensaios não destrutivos usados na base do elevador cremalheira às luzes da norma AWS D1.1. (Código de Soldagem Estrutural Aço, tradução de: Structural Welding Code - Steel). A escolha de parâmetros de soldagem é uma etapa importante do processo de soldagem, influenciando diretamente no aporte térmico fornecido às juntas soldadas. Esse valor de aporte térmico juntamente com a distribuição de temperatura nas juntas soldadas fornece a o projetista condições de prever o tamanho da zona termicamente afetada, o tipo de microestrutura formada e consequentemente prevenir os efeitos das tensões residuais. Como metodologia foram revisados os conceitos do processo de soldagem e dos ensaios não destrutivos, os requisitos de pré-qualificação (Especificação do Procedimentos de Soldagem) e documentação Técnica. Aplicados os ensaios, os procedimentos e padrões estabelecidos de forma a garantir os requisitos da norma.

Palavras-Chave: Guinchos cremalheira, Elevador, Base de guinchos;

\begin{abstract}
The study aims to present the manufacturing process and the non-destructive testing used on rack lift base to the lights of AWS D1.1. (Steel Welding Code, Structural Welding Code - Steel). The choice of welding parameters is an important step in the welding process, directly influencing the thermal input supplied to the welded joints. This thermal input value together with the temperature distribution in the welded joints provides the designer with the ability to predict the size of the thermally affected zone, the type of microstructure formed and consequently to prevent the effects of the residual stresses. As a methodology, the concepts of the welding process and non-destructive tests, the pre-qualification requirements (Specification of Welding Proce-dures) and Technical documentation were reviewed. Applied the tests, procedures and standards established in order to guarantee the requirements of the standard.
\end{abstract}

Key-words: Screw Winch, Elevator, Winch base. 


\section{Introdução}

O setor de construção civil no país tem recebido vários investimentos e incentivos do setor público e privado nos últimos anos. Assistimos, sim, uma crescente oferta na área de infraestrutura no Brasil. No setor de construção vertical, a construção de imóveis residenciais e comerciais foi estrondosa. 0 setor imobiliário é um dos que mais emprega nossa mão de obra, não só a nível local ou regional, mas também a nível nacional. Até os dias atuais, várias construtoras cresceram e outras tantas surgiram, galgando os mesmos passos de suas percussoras.

Com o aumento no número de estruturas em construção no nosso país, tem-se crescido a preocupação com os processos de fabricação delas, notadamente nos processos que envolvem estruturas metálicas. Os projetos de construção são regidos pela Norma AWS D1.1 (America n Welding Society) [1], que delimita o passo-a-passo do processo de fabricação e indicando quais são as variáveis no processo e fornecendo algumas soluções que podem ser aplicadas no processo de fabricação para obtermos um resultado satisfatório.

Um dos setores que nos últimos anos obteve um crescimento bastante significativo foi o de construção vertical. E neste seguimento, alguns equipamentos são de extrema importância para o andamento da obra, podem os destacar dois deles: Grua e Guincho Cremalheira. Este último, é o responsável pelo transporte vertical treen os pavimentos da obra de pessoas, materiais, ferramentas e demais equipamentos necessários à atividade.

Há vários fabricantes de guinchos cremalheira de marca nacional que estão concorrendo com marcas importadas principalmente do mercado chinês, que predominantemente entraram no mercado nacional através de diversos incentivos à importação e também aproveitando o aquecimento do mercado interno no setor imobiliário. Além da Norma Regulamentadora NR18 - CONDIÇÕES E MEIO AMBIENTE DE TRABALHO NA INDÚSTRIA DA CONSTRUÇÃO, também se adota os conceitos da Norma Regulamentadora NR12 - SEGURANÇA NO TRABALHO EM MÁQUINAS E EQUIPAMENTOS, para garantir o sucesso das atividades de manutenção e operação com os equipamentos [2] e [3].

No processo de fabricação e soldagem dos elementos que compõem o guincho cremalheira as empresas precisam seguir alguns requisitos e normas que regem este tipo de equipamento. A norma recomendada para ser seguida durante o processo de fabricação de estruturas metálicas em aço é a norma internacional American Welding Society AWS D1.1. [1].

No processo de fabricação do guincho cremalheira, o item soldagem é o de maior importância, por compreender quase que a totalidade do processo de fabricação. Por se tratar de um equipamento de movimentação de cargas e pessoas, deve-se seguir criteriosamente os cuidados e preceitos descritos na AWS D1.1 [1], no tocante aos critérios de aceitação dos ensaios para assegurar que o produto final não apresente defeitos substanciais, garantindo assim a qualidade no processo de fabricação. Além do processo de soldagem, pode-se destacar, sem minimizar suas devidas importâncias, os componentes elétricos, eletrônicos e mecânicos.

No processo de soldagem da estrutura do guincho, será dada uma ênfase especial às bases do guincho. Por se tratar de um item importante na montagem do equipamento ele suporta e transmite ao solo os esforços que o guincho sofre durante sua operação [1].

\subsection{Requisitos iniciais}

O ponto de partida, neste estudo, para atender 0 que a AWS D1.1 determina é se ter uma série de procedimentos que nos garantirá um processo homogêneo e passível de ser rastreado em toda a cadeia produtiva [1].

A EPS - especificação de procedimento de soldagem, estabelece quais itens são importantes e que devem ser considerados nos procedimentos [1]. Estas variáveis foram previamente testadas.

A RQPS - Registro de qualificação de procedimento de soldagem, registra e atesta que o procedimento usado é adequado para garantir a qualidade desejada conforme a norma [1]. A comprovação deste registro é feita através de alguns ensaios determinados pela norma, Ex.: dobramento, tração, impacto e analise química.

O soldador também será qualificado, pois uma solda de qualidade também depende da habilidade do colabora-dor em executar tal procedimento [4] e [5].

O Registro de qualificação do soldador (Welder Qualification Record) é um documento que registra os dados relativos a comprovação da habilidade do sold ador em executar tal tarefa. A comprovação da habilidade do soldador é feita através de testes específicos descritos na norma AWS D1.1. Os testes serão feitos em todos os inte-grantes da equipe envolvida no processo de soldagem da base do elevador cremalheira. A utilização do registro, garante a uniformização do procedimento e das condi 
ções especificadas de soldagem para controle do processo e possíveis e eventuais rastreabilidades [1].

\subsection{Pré-qualificação da WPS (Welding Procedure specifications - Especificações de procedimentos de soldagem)}

\subsection{Processo de Soldagem}

Será utilizado, o processo SMAW - Shielded Metal Arc Welding - Soldagem com eletrodo revestido. Outros processos podem ser utilizados, desde que as WPS sejam qualificadas por meio de testes comprobatórios conforme a AWS D1.1 [1].

Todas as WPS pré-qualificadas deverão ser escritas, as que não estiverem em conformidade devem ser qualificadas por meio de testes [1].

Tabela 3.1

Metal Base Pré-qualificado - Combinações do Metal de Adição para Resistência Correspondente (ver 3.3)

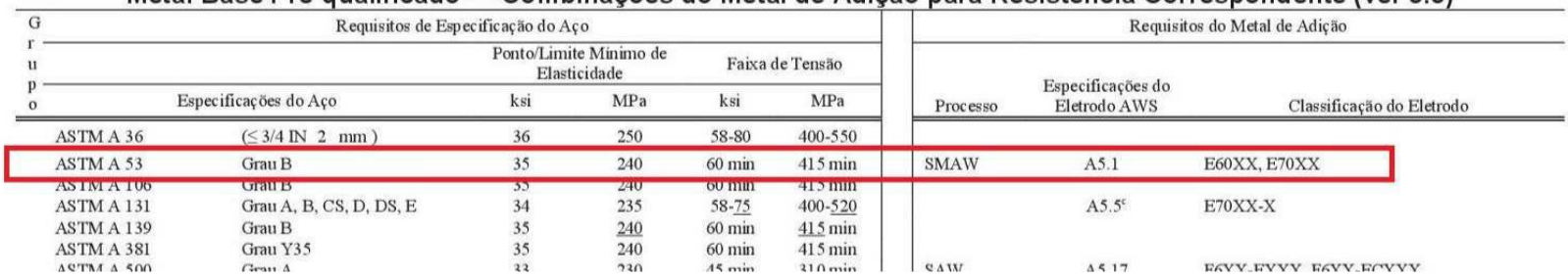

Figura 1: A tabela 3.1. Metal Base Pré-qualificado - combinação do metal de adição para resistência correspondente.

Fonte: AWS D1.1 [1].

Apenas metal de base e metais de adição relacionados na tabela 3.1 podem ser utilizados em WPS pré-qualificadas. Para metais que não estão listados na tabela 3.1, verifica-se o item 4.2.1 da AWS D1.1 [1].

A Tabela abaixo, Figura 2, relaciona a resistência entre metal de base e o metal de adição [1].

\begin{tabular}{|c|c|c|}
\hline Relações & Metal(is) Base & $\begin{array}{l}\text { Resistencia do } \\
\text { Metal de Adição, } \\
\text { Relação Exigida }\end{array}$ \\
\hline \multirow{2}{*}{ 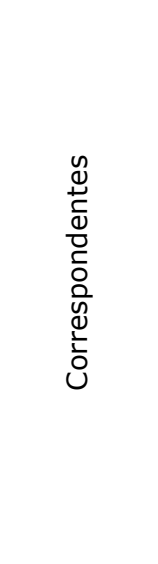 } & $\begin{array}{c}\text { Qualquer aço } \\
\text { para si mesmo } \\
\text { ou qualquer } \\
\text { aço para outro, } \\
\text { no mesmo } \\
\text { grupo }\end{array}$ & $\begin{array}{l}\text { Qualquer metal } \\
\text { de adição listado } \\
\text { no mesmo grupo }\end{array}$ \\
\hline & $\begin{array}{c}\text { Qualquer aço } \\
\text { em um grupo } \\
\text { para qualquer } \\
\text { aço em outro } \\
\text { grupo }\end{array}$ & $\begin{array}{c}\text { Qualquer metal } \\
\text { de adição listado } \\
\text { para cada grupo } \\
\text { de tensão. [Os } \\
\text { eletrodos de } \\
\text { SMAW devem ser } \\
\text { classificados } \\
\text { como tendo um } \\
\text { baixo nível de } \\
\text { hidrogênio.] }\end{array}$ \\
\hline 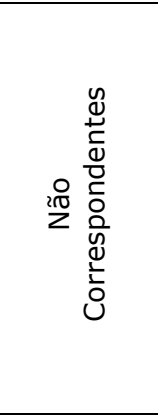 & $\begin{array}{c}\text { Qualquer aço } \\
\text { para qualquer } \\
\text { aço em } \\
\text { qualquer grupo }\end{array}$ & $\begin{array}{c}\text { Qualquer metal } \\
\text { de adição listado } \\
\text { em um grupo de } \\
\text { tensão abaixo do } \\
\text { grupo de menor } \\
\text { tensão. [Os } \\
\text { eletrodos de } \\
\text { SMAW devem } \\
\text { ser classificados } \\
\text { como tendo um } \\
\text { baixo nível de } \\
\text { hidrogênio.] }\end{array}$ \\
\hline
\end{tabular}

Figura 2: Tabela de relação de resistência entre o metal de base e o de adição.

Fonte: AWS D1.1 [1].

\subsection{Combinação metal de base/metal adição}

A tabela 3.1 na figura 1 , será apresentada de forma fracionada em virtude da restrição de espaço. Nela, permite-se usar, para o aço ASTM A53 grau B, o eletrodo com a especificação AWS 5.1 bem como a classificação AWS E60XX ou AWS E70XX. Será adotado o eletrodo AWS E7018 [6].

A Tabela na Figura 2 relaciona a resistência entre metal de base e o metal de adição. Ela deve ser utilizada em conjunto com a tabela 3.1 para determinar se são necessários metais de adição correspondentes ou não [1].

\subsection{Requisitos de temperaturas mínima de pré-aquecimento e interpasse}

As temperaturas de pré-aquecimento e interpasse devem ser suficientes para não provocar trincas. Para o aço ASTM A53 grau B, a espessura a ser utilizada é de $1 / 8^{\prime \prime}$ e estando entre $1 / 8^{\prime \prime}$ e $3 / 4$ ". Conclui-se que não há necessidade de pré-aquecimento [1].

\subsection{Limitação de variáveis de WPS}




\section{Materiais e Métodos}

\subsection{Ensaios não destrutivos - análise}

Nos documentos do contrato de fabricação devem estar designados a especificação e a classificação do metal de base. Para outros metais de base encontram-se na tabela 3.1 página 90 ou tabela 4.9 página 169 da AWS D1.[1].

Foram executados 4 (quatro) ensaios não destrutivos nas juntas soldadas. A saber: Visual, liquido penetrante, partícula magnética e ultrassonografia.

Antes dos ensaios por liquido penetrante, partícula magnética e ultrassom, deve-se realizar o ensaio visual de todas as juntas soldadas. Neste estudo foram inspecionadas 5 (cinco) das juntas soldadas, conforme demonstradas nos registros abaixo.

\subsection{Inspeção Visual}

\subsubsection{Critério de Preparação para ensaio visual}

O local onde se realiza a operação de inspeção deve estar limpo, organizado e suficientemente claro, com iluminação artificial ou natural [7], [8] e [9].

Quando se utiliza iluminação artificial, deve-se prever a intensidade adequada para evitar reflexos na superfície, especialmente em materiais reflexivos como alumínio e aço inoxidável. A inspeção visual deve ser feita em três etapas: verificação antes, durante e após o processo de soldagem [1] e [4].

$\mathrm{Na}$ junta 1, Figura 4, a escória deve ser removida de todas as soldas finalizadas, a solda e o metal de base adjacente devem ser limpos por escovação ou outros meios adequados [1].

$\mathrm{Na}$ junta 2, Figura 5, percebe-se respingos de solda firmemente aderentes que remanesceram após a operação de limpeza e que são aceitáveis, a menos que sua remoção seja requerida [1].

$\mathrm{Na}$ junta 3, Figura 6, foram detectados mordedura, respingo de solda e porosidade. $\mathrm{Na}$ junta 4 , figura 7 , foram detectados respingos de solda e inclusão de escoria.

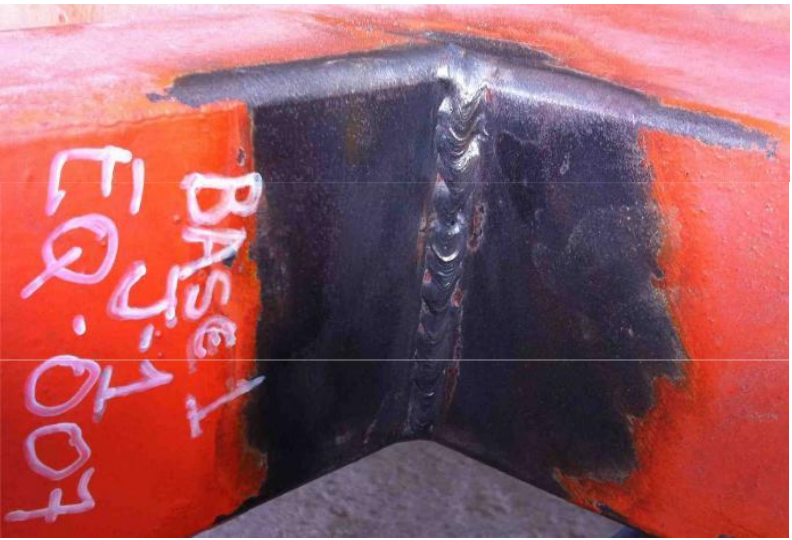

Figura 4: Ensaio visual da Junta 1 Fonte: autor

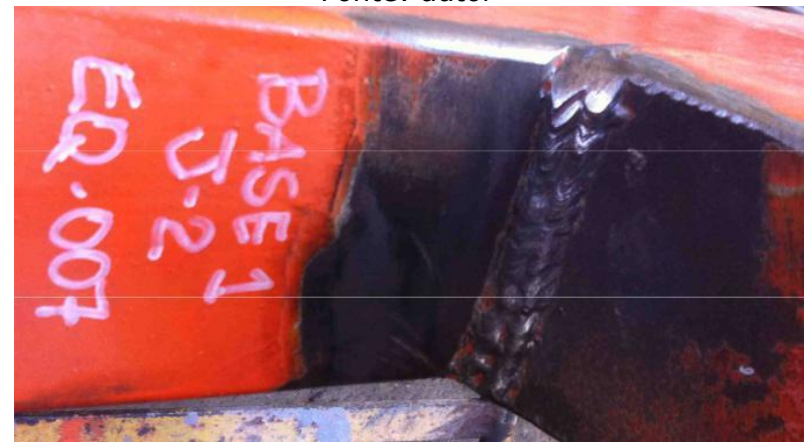

Figura 5: Ensaio visual da junta 2 Fonte: autor

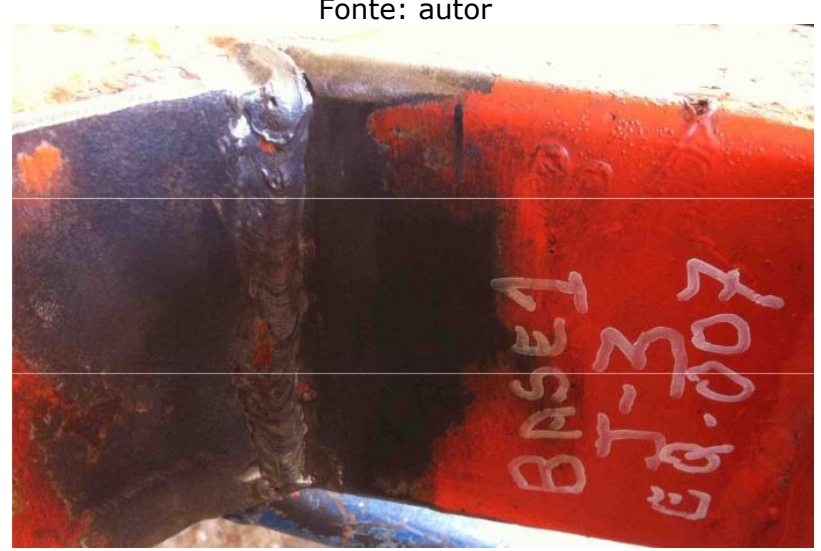

Figura 6: Ensaio visual da junta 3 Fonte: autor

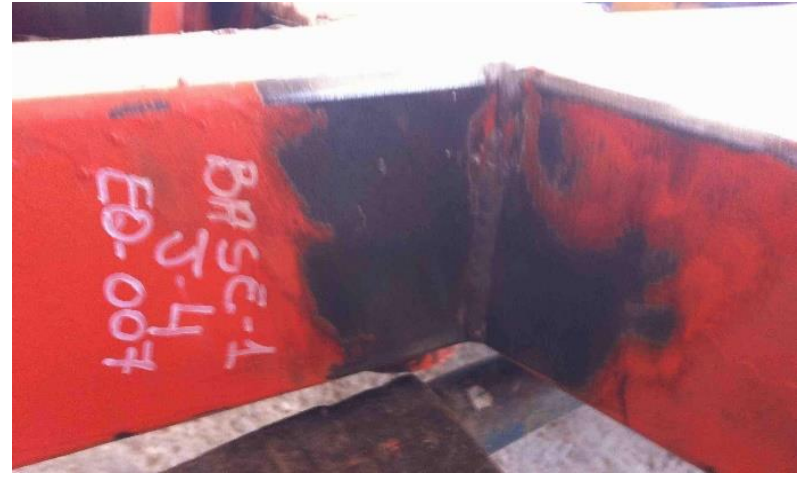

Figura 7: Ensaio visual da junta 4 Fonte: autor

http: / / dx.doi.org/10.25286/ repa.v2i4.711 


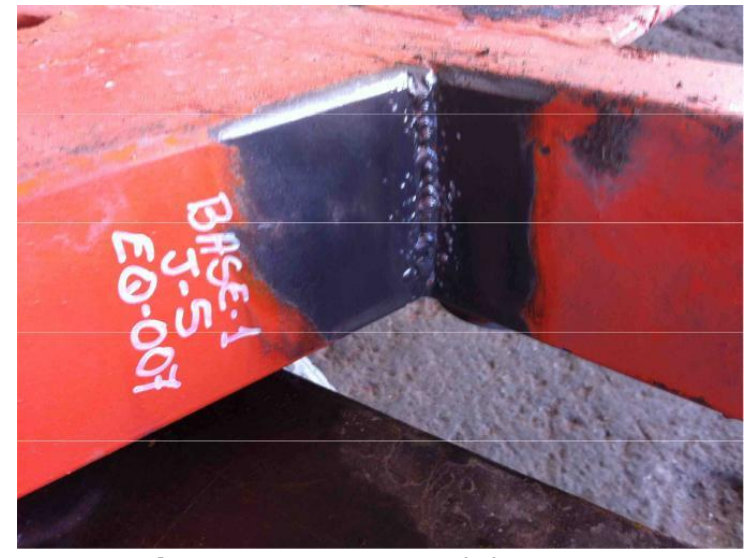

Figura 8: Ensaio visual da junta 5 Fonte: autor

$\mathrm{Na}$ junta 5, Figura 8, foram detectados mordeduras, inclusões de escórias e porosidades.

Através destas inspeções foram detectadas as mordeduras como uma das descontinuidades do processo de soldagem. Os respingos de soldas e aberturas de arco também ficaram bastante evidentes na junta soldada. Contudo, estas duas ultimas devem ser removidas logo após a conclusão do processo de soldagem.

\subsection{Ensaio com Líquido Penetrante}

\subsubsection{Critério de Preparação para ensaio com líquido penetrante}

A figura 9 apresenta a base do guincho onde as juntas devem ser analisadas por LP.

Antes da execução do ensaio a superfície deverá estar isenta de resíduos, sujeiras, óleo, graxa, e qualquer outro contaminante que possa obstruir as possíveis aberturas a serem detectadas [1] e [4].

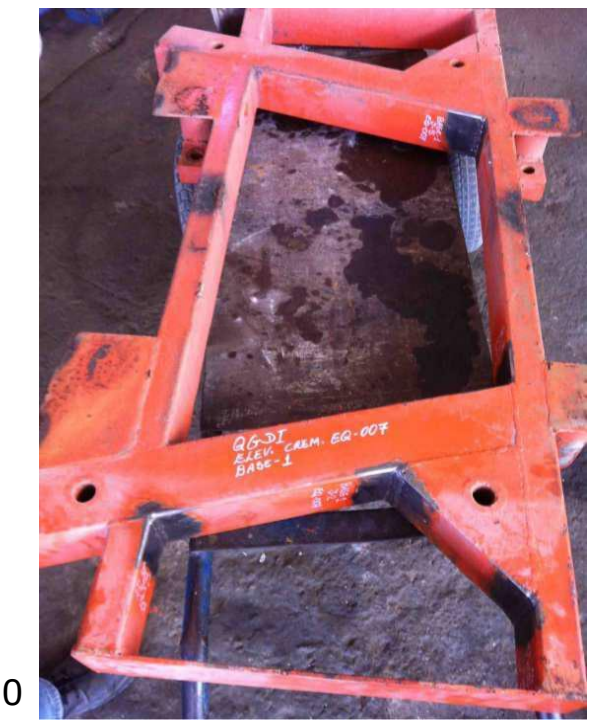

Figura 9: Visão geral da peça a ser ensaiada Fonte: Autor

Após a execução da limpeza das 5 (cinco) juntas a serem ensaiadas, elas foram identificadas conforme as Figuras 4, 5, 6, 7 e 8. Que compõem a base apresentada na Figura 9.

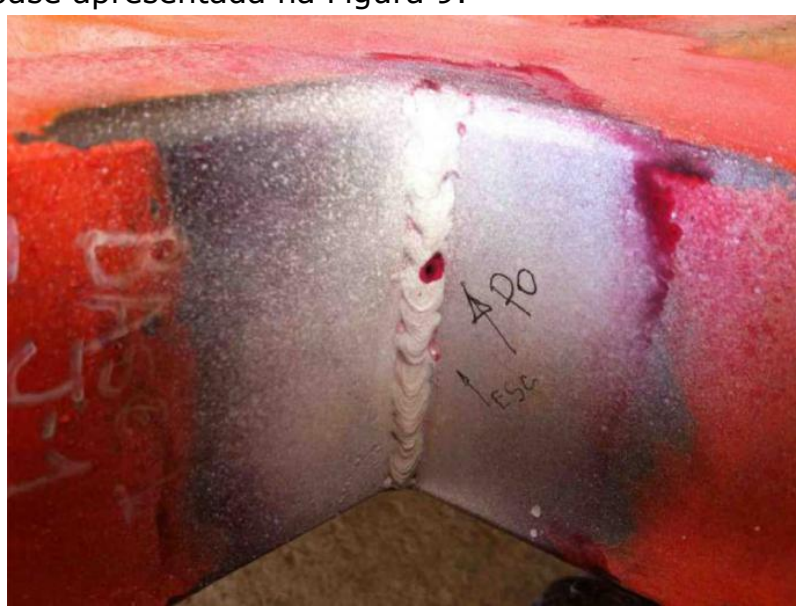

Figura 10: Junta 1

Fonte: autor

Na junta 1, Figura 10, após a aplicação do revelador percebe-se que no cordão de solda aparece uma porosidade (PO) que é causada principalmente pelo aprisionamento de gases na poça de fusão que não sairam para a atmosfera. Esta ocorrência está relacionada aos procedimentos de soldagem, onde os gases mais comuns encontrados são: Nitrogênio, Oxigênio e Hidrogênio. Observa-se também inclusão de escoria (ESC) que é provocada, principalmente pela deficiente limpeza prévia na margem da solda.

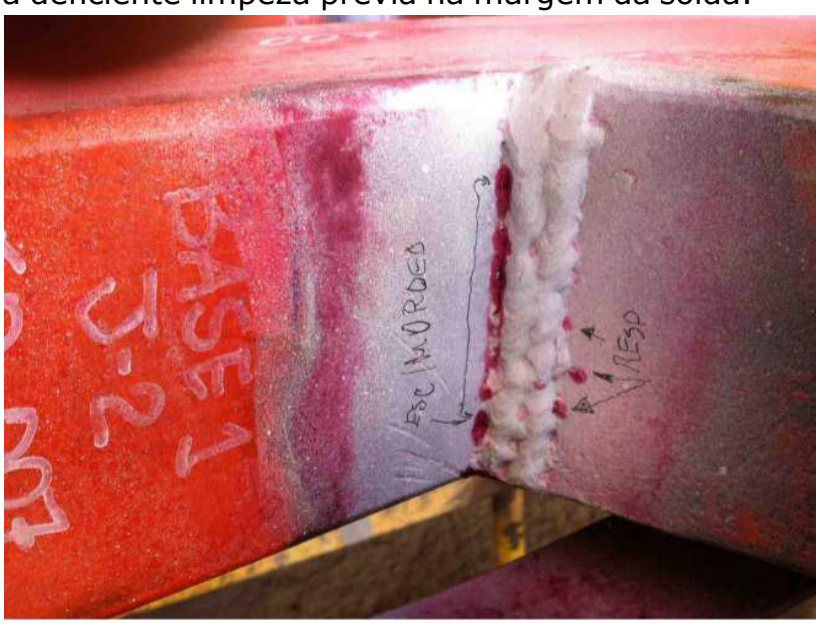

Figura 11: Junta 2 Fonte: autor 
Na junta 2, Figura 11, Observa-se a presença de mordeduras (MO) de aproximadamente $2 \mathrm{~mm}$ de profundidade e respingos de soldas (RESP). Ambas já detectadas no ensaio visual.

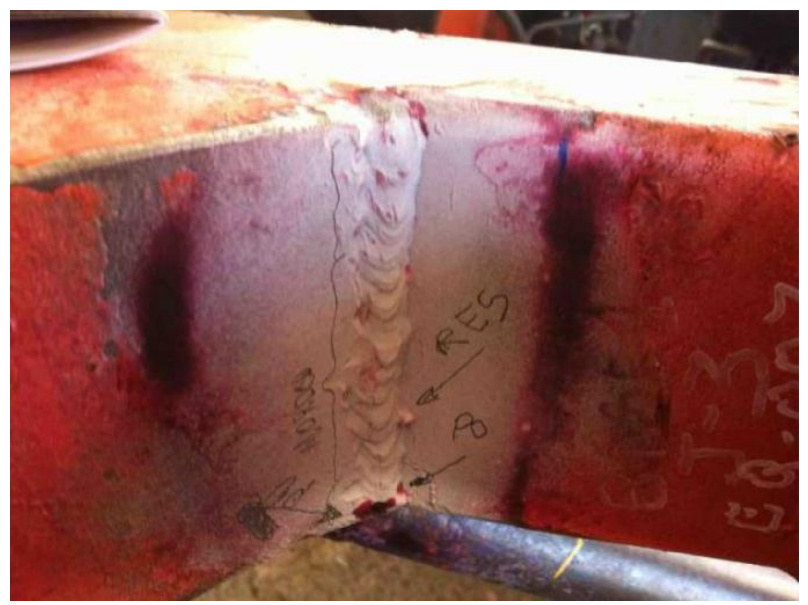

Figura 12: Junta 3

Fonte: autor

Na junta 3, Figura 12, detectamos 3 (três) descontinuidades apresentando-se de forma distinta: Mordedura (MO), Respingo de solda (RES) e Porosidade (PO). A mordedura é caracterizada pela fusão da superficie da chapa do metal de base próxima à margem do cordão. Em alguns casos a mordedura pode ser muito perigosa, visto que cria um entalhe na zona de ligação e concentra ainda mais tensão neste local. $O$ respingo de solda foi indicado por uma seta e a porosidade também. Mordedura e respingo de solda já detectadas no ensaio visual.

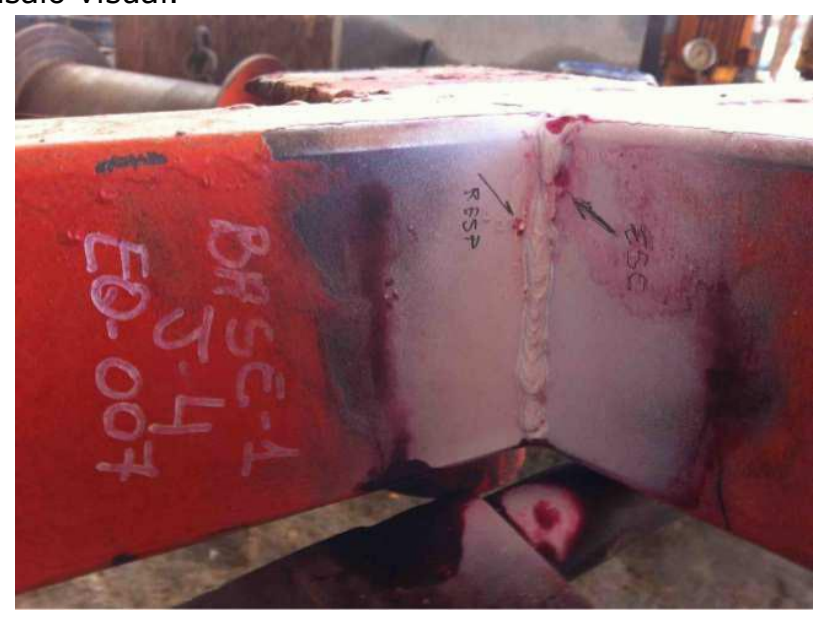

Figura 13: Junta 4

Fonte: autor

$\mathrm{Na}$ junta 4, Figura 13, Observa-se um respingo de solda (RESP) e uma inclusão de escoria (ESC) decorrente de uma limpeza prévia deficiente.
Ambas indicadas na foto e detectadas na inspeção visual.

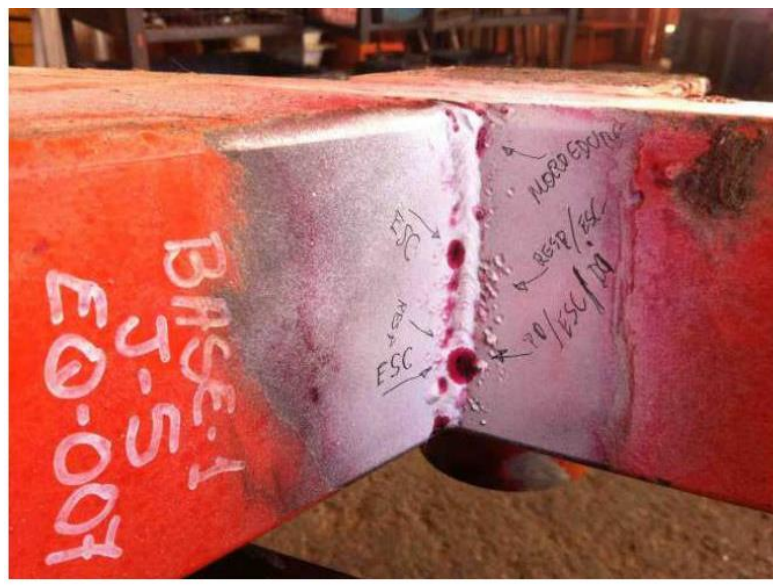

Figura 14: Junta 5

Fonte: autor

Na junta 5, Figura 14, foi a que mais apresentou descontinuidades, tais como: Mordeduras (provocada por corrente eletrica elevada), inclusão de escórias, porosidade e deposição insuficiente. A mordedura e o respingo de solda foram detectadas também na inspeção visual.

\subsection{Ensaio com Partícula Magnética}

Os ensaios com partículas magnéticas (MT) foram realizados em todas as 5 (cinco) juntas soldadas pelo processo SMAW (shielded Metal Arc Welding - Soldagem com eletrodo revestido) [4].

$O$ equipamento usado para o ensaio por PM detecta descontinuidades superficiais $e$ subsuperficiais de até $3 \mathrm{~mm}$ de profundidade. A técnica utilizada foi a do Yoke, que consiste na magnetização por indução em campo magnético gerado por um eletroímã em forma de "U" invertido [8], conforme demonstrados nas figuras $15,16 \mathrm{e}$ 17. 


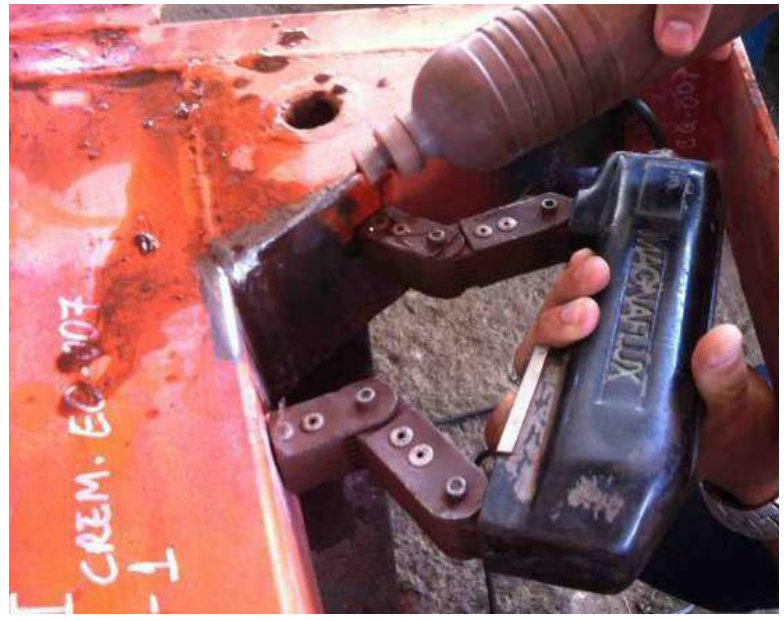

Figura 15: Ensaio com particula magnética Fonte: autor

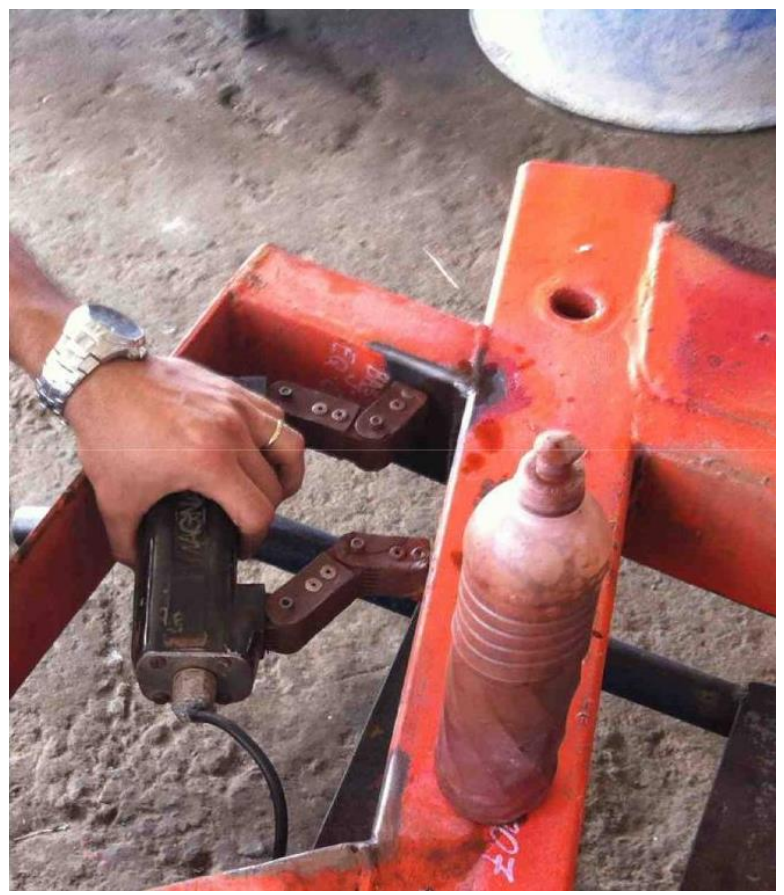

Figura 16: Ensaio com particula magnética Fonte: autor

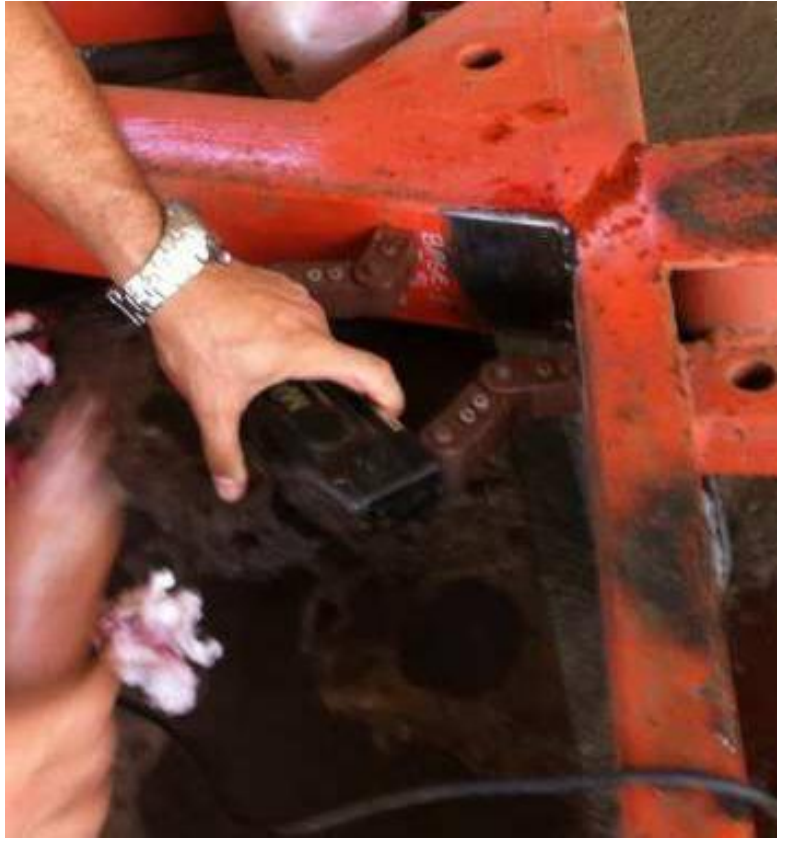

Figura 17: ensaio com particula magnetica Fonte: autor

Foram ensaiadas as 5 (cinco) juntas soldadas e em nenhuma delas foi detectada a presença de trincas. A faixa de alcance do equipamento é de até $3 \mathrm{~mm}$ sob a superficie.

\subsection{Ensaio por Ultrassom}

O último ensaio realizado nas juntas foi o de ultrassom (US) [7]. Utilizou-se o modelo FLAW DETECTOR - KFD35 com sonda para detecção de falhas. Cabeçote A n-gular referência MWB70N4, MWB60N4 e cabeçote de duplo cristal MSE4H. A espessura da parede da estrutura é de $1 / 8^{\prime \prime}$ $(3,175 \mathrm{~mm})$.

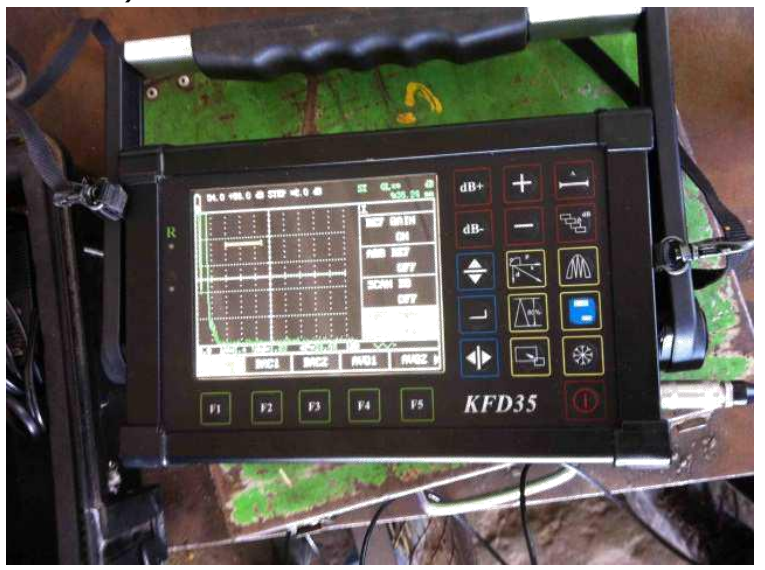

Figura 18: aparelho de teste por ultrassom Fonte: autor 


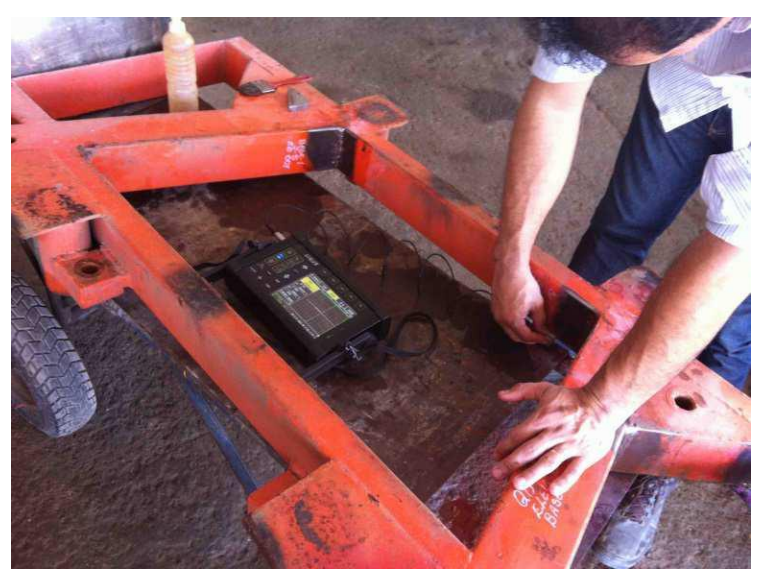

Figura 19: Ensaio por ultrassom Fonte: autor

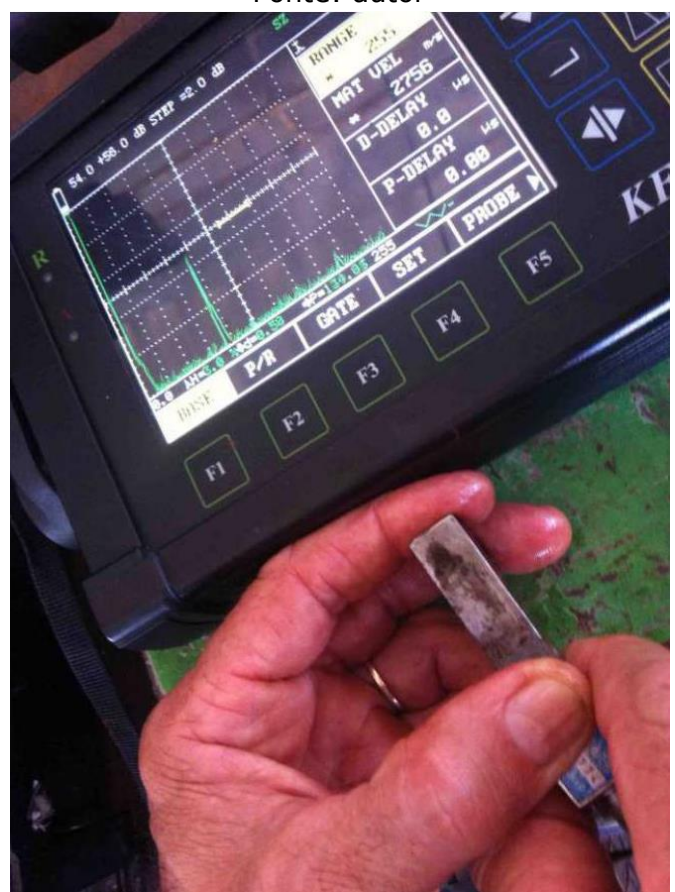

Figura 20: demonstração no gráfico de como o aparelho detecta a descontuidade Fonte: autor

Não foram detectadas descontinuidades com o aparelho de ultrassom, Figura 19. Para ilustrar como a descontinuidade apareceria na tela, usa-se um bloco padrão onde é simulada descontinuidade, figura 20. O resultado aparece no display com um ganho elevado, indicado em linha verde próximo ao centro do display.

Aberturas de arco fora da área de soldas permanentes devem ser evitadas em qualquer metal base. Trincas ou imperfeições causadas por aberturas de arco devem ser retificadas a um contorno suave e verificados para assegurar a estabilidade, segundo os criterios de aceitação AWS D1.1 [1].

\section{Resultado e discussões}

Após a realização de todos os devidos ensaios, foram notados os diversos defeitos que podem nortear tal procedimento de soldagem executado, caso não seja devidamente feito a identificação das variáveis essenciais na WPS.

A norma AWS D1.1 indica que deve haver fusão completa entre as camadas. Logo, onde foram encontradas as descontinuidades de porosidade, mordedura e inclusão de escoria, estas, são consideradas defeitos. Sendo assim, estas anomalias apresentadas na junta soldada poderá alterar o seu desempenho e eficiência. Assim relatado no item 2 da tabela 6.1 da norma AWS D1.1, [1].

\subsection{Critério de aceitação para inspeção visual}

Todas as soldas devem ser inspecionadas visualmente e devem ser aceitáveis caso os critérios da Tabela 6.1 da norma AWS D1.1 sejam satisfeitos [1].

No item 2 - Fusão de Metal Base/de Adição, na tabela 6.1 menciona que, para conecções nãotubulares estaticamente carregadas "deve existir fusão completa entre camadas adjacentes de metal de solda e entre metal de solda e metal base" [1]. Neste caso, detectamos várias descontinuidades: Mordeduras, inclusão de escória, porosidade em todas as juntas executadas. Logo, por este critério, as soldas efetuadas nestas juntas estão reprovadas.

Nas juntas 3, 4 e 5 a soma dos tamanhos da mordedura, excede o critério proposto pela norma AWS D1.1 [1], conforme descrito no item 7 abaixo. O que também indica reprovação destas juntas por este critério.

No item 7 - Mordedura, na tabela 6.1 menciona que, para conexões não-tubulares estaticamente carregada s: "Para material com espessura menor que 1 in [25 mm] , a mordedura não deve exceder $1 / 32$ in [1 $\mathrm{mm}]$, com a seguinte exceção: A mordedura não deve exceder $2 \mathrm{~mm}$ para qualquer comprimento acumulado até 2 in $[50 \mathrm{~mm}$ ] em quaisquer 12 in [300 mm]" [1].

Como a espessura da base é de $1 / 8^{\prime \prime}(3,175$ $\mathrm{mm}$ ) usa-se o critério acima. Na junta-3, figura 12 , fica evidente a presença de mordedura acima de 2

http: / / dx.doi.org/10.25286/repa.v2i4.711 
$\mathrm{mm}$. Na junta-5, figura 14, observamos mordedura acima de $1 \mathrm{~mm}$, na junta-4, figura 13 , tem-se mordedura de $3 \mathrm{~mm}$. Logo, em cada junta, por este critério as juntas estão reprovadas.

A soma dos comprimentos das porosidades encontradas também é um critério de reprovação, conforme descrito no item 8 abaixo, da Tabela 6.1 da norma AWS D1.1 [1].

No item 8 - Porosidade, na tabela 6.1 para conexões não-tubulares estaticamente carregadas comenta-se que: "Soldas em chanfro em juntas de topo transversais à direção da tensão de tração computada não devem ter porosidade visível. Para todas as outras soldas em chanfro e para soldas de filete, a soma de porosidade visível de diâmetro de $1 / 32$ in [ $1 \mathrm{~mm}$ ] ou maior não deve exceder $3 / 8$ in [10 mm] em qualquer polegada linear de solda e não deve exceder $3 / 4$ in [20 mm] em qualquer comprimento de solda de 12 in [300 mm]" [1].

Foram detectadas porosidade nas juntas: 1, 2, 3 e 5 . Com dimensões acima das mencionadas. Logo, elas foram reprovadas.

\subsection{Critério de aceitação para ensaio por líquido penetrante}

Soldas que são sujeitas a PT (líquido penetrante), além da inspeção visual, devem ser avaliadas com base nos requisitos aplicáveis para inspeção visual. O teste deve ser realizado em conformidade com 6.14.5 o que for aplicável.

"6.14.5 PT. Para detectar descontinuidades abertas na superfície, PT pode ser usado. Os métodos padrão estabelecidos em E 165 da ASTM devem ser usados para inspeção PT, e os padrões de aceitação devem estar em conformidade com a Cláusula 6, Parte $C$, deste código, o que for aplicável" [1].

"O código não inclui critérios de aceitação para t este por liquido penetrante de líquido baseado em sangramento da tintura. Quando PT é usado, a aceitação de qualquer descontinuidade deve ser baseada em uma avaliação visual da descontinuidade após a remoção do meio indicador.

Quando a descontinuidade não pode ser vista (com ampliação, se requerido) depois da remoção do meio indicador, a avaliação deve ser baseada no tamanho e natureza da indicação PT. Observação 5 do penetrante conforme ele sangra irá fornecer informações úteis a respeito da natureza da descontinuidade" [1].

Isto demostra que a avaliação a ser feita após a aplicação do método é visual, avaliando as descontinuidades apresentadas. Evidencia-se em todas as juntas que há descontinuidades severas. Logo, por este critério, as soldas foram reprovadas.

\subsection{Critério de aceitação para ensaio de partícula magnética}

Soldas que são sujeitas a MT (Particula Magnetica), além da inspeção visual, devem ser avaliadas com base nos requisitos aplicáveis para inspeção visual. O teste deve ser realizado em conformidade com 6.14.4 o que for aplicável. [1].

"6.14.4 MT. Quando MT é usado, o procedimento e técnica devem estar em conformidade com E 709 da ASTM, e o padrão de aceitação deve estar em conformidade com a Cláusula 6 - Parte C (Anexos), deste código, o que for aplicável" [1]

"Os critérios de aceitação MT inclusos no código são baseados no tamanho da descontinuidade real, e não no tamanho da descontinuidade como indicado pelo meio de indicação MT. Quando superfícies de descontinuidade s são reveladas por meios MT, a aceitação deve ser baseada em uma medida direta visual da descontinuidade real. Quando a descontinuidade não pode ser detectada visualmente (com ampliação se requerido) depois da remoção do meio indicador, a avaliação deve ser baseada no tamanho e natureza da indicação MT. Para descontinuidades sub - superfície, a avaliação deve ser baseada no tamanho da indicação de descontinuidade porque a descontinuidade não está acessível.

\subsection{Critério de aceitação de ensaio por ultrassom}

Os procedimentos e padrões estabelecidos na Parte F da AWS D1.1 [1] devem governar o UT de soldas em chanfro e HAZs entre as espessuras de $5 / 16$ in e 8 in [ $8 \mathrm{~mm}$ e $200 \mathrm{~mm}$ ], quando tal teste é requerido pelo item 6.14 deste código. Para espessuras menores que $5 / 16$ in [ $8 \mathrm{~mm}$ ], ou maiores que 8 in $[200 \mathrm{~mm}]$, o teste deve ser realizado em conformidade com o Anexo S. 
"S12.1 Amplitude. Os critérios de aceitaçãorejeição da tabela S.1 devem se aplicar quando amplitude e comprimento são os maiores fatores e dimensão máxima da descontinuidade não for conhecida ou especificada" [1].

"S12.2 Tamanho. Quando a dimensão máxima permissível de descontinuidade (altura, comprimento e profundidade) é conhecida e é especificada pelo Engenheiro, a dimensão real (altura, comprimento e profundidade) devem ser determinadas e reportados. Avaliação final e aceitação/rejeição devem ser do Engenheiro" [1].

\section{Conclusões}

Algumas descontinuidades foram detectadas nos ensaios realizados nas 5 (cinco) juntas. Em virtude da não realização da WPS, EPS e RQPS que antecede o processo de soldagem, conclui-se que o surgimento de defeitos se tornou bastante evidente. Daí conclui-se a real importância desta etapa no processo de soldagem.

Os defeitos detectados foram: Porosidade, Mordedura, Inclusão de escória e respingo de solda. Estas descontinuidades, que foram evidenciadas através dos ensaios não destrutivos, comprometem a nível de norma a integridade estrutural do equipamento soldado, ou seja, não atendem aos critérios de aceitação da norma AWS D1. 1. [1];

Faz-se necessário assim, haver uma interação para a reparação destas juntas, logo após a conclusão de cada junta. O retrabalho é indesejável, por comprometera qualidade e produtividade do processo. Sendo assim, é mais eficiente, observar os cuidados e critérios estabelecidos na AWS D1.1 [1], para se realizar os devidos procedimentos visando obter-se uma junta de qualidade estrutural.

\section{Referências}

[1] AWS - AMERICAN WELDING SOCIETY. Código de Soldagem Estrutural - Aço. Tradução de: Structural Welding Code Steel. AWS D1.1/D1.1M. Miami, FL EUA. 2010 - 22a Edição.

[2] MINISTERIO DO TRABALHO E EMPREGO MTE - NR12: Segurança no trabalho em maquinas e equipamentos. Out./2013
[3] MINISTERIO DO TRABALHO E EMPREGO MTE - NR18 : Condições e meio ambiente de trabalho na indústria da construção. Out./2013

[4] T. Okumura, C. Taniguchi. Engenharia de soldagem e aplicações. Livros Técnicos e Científicos Editora S. A., Rio de Janeiro, 1982.

[5] E. Wainer, S. Brandi, F. Mello. Soldagem processos e metalurgia. Editora Edgard Blucher Ltda, São Paulo - SP. 9a Reimpressão 2013.

[6] AMERICAN SOCIETY FOR TESTING AND MATERIALS. ASTM A53/A53M - 12 Standard Specification for Pipe, Steel, Black and Hot-Dipped, Zinc-Coated Welded and Seamless. 2012 - 10a Edição.

[7] R. Andreucci. Assessoria e Serviços Técnicos Ltda. Ensaio por Ultrassom. Abendi. Edição: Mai./2014 www.Infosolda.com.br, Jun.2017.

[8] R. Andreucci. Assessoria e Serviços Técnicos Ltda. Ensaio por Partícula Magnética. Abendi. Edição: Jan./2009 www.Infosolda.com.br, Jun.2017.

[9] R. Andreucci. Assessoria e Serviços Técnicos Ltda. Ensaio por Liquido Penetrante. Abendi. Edição: Fev./2014 www.Infosolda.com.br, jun.2017. 